
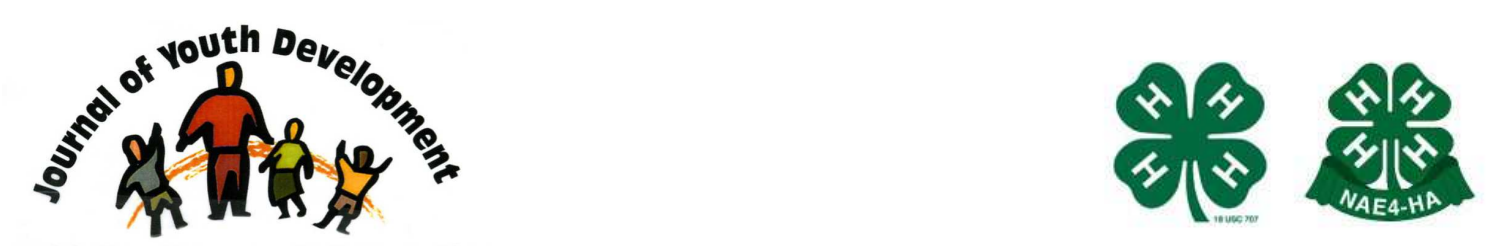

Bridging Research \& Practice

\title{
Potential Protective Effect of the Community Involvement Asset on Adolescent Risk Behaviors
}

Sharon Rodine, M.Ed.

Oklahoma Institute for Child Advocacy

Oklahoma City, OK

srodine@oica.org

Roy F. Oman, Ph.D.

University of Oklahoma Health Sciences Center

Oklahoma City, OK

Roy-Oman@ouhsc.edu

Sara K. Vesely, Ph.D.

University of Oklahoma Health Sciences Center

Oklahoma City, OK

Sara-Vesely@ouhsc.edu

Cheryl B. Aspy, Ph.D.

University of Oklahoma Health Sciences Center

Oklahoma City, OK

Cheryl-Aspy@ouhsc.edu

Eleni Tolma, MPH, Ph.D.

University of Oklahoma Health Sciences Center

Oklahoma City, OK

Eleni-Tolma@ouhsc.edu

LaDonna Marshall

Oklahoma Institute for Child Advocacy

Oklahoma City, OK

Imarshall@oica.org

Janene Fluhr

University of Oklahoma Health Sciences Center

Oklahoma City, OK

Janene-Fluhr@ouhsc.edu 


\title{
JOURNAL OF YOUTH DEVELOPMENT bridging research and practice
}

Sharon Rodine and LaDonna Marshall Oklahoma Institute for Child Advocacy

Roy F. Oman, Sara K. Vesely, Cheryl B. Aspy, Eleni Tolma and Janene jFluhr University of Oklahoma Health Sciences Center

\begin{abstract}
The potential of Community Involvement as a protective factor (youth asset) for eight adolescent risk behaviors was examined in this study. Cross-sectional data were collected from a randomlyselected population using in-home, in-person interviews in racially diverse inner-city neighborhoods of two Midwestern cities. Research participants were teenagers $(n=1,278)$ and parents of the teenagers $(n=1,278)$. Data included demographic variables; eight adolescent risk behaviors, including sexual activity, violence and the use of tobacco, alcohol and drugs. This study found youth with the Community Involvement asset were significantly $(p<.05)$ more likely to: never have had sexual intercourse; not use tobacco or drugs; not use alcohol if living in a one-parent family; not carry a weapon, or never have been arrested. Involvement in community volunteer experiences may hold potential for strengthening youth development and prevention programs focused on reducing youth risk-taking behaviors.
\end{abstract}

\section{Introduction}

Although the rates of certain adolescent health risk behaviors, such as teen pregnancy, tobacco use and substance abuse, have declined during the past decade, the sheer number of young people involved in a variety of health risk behaviors in the U.S. remains far too high. Moreover, as the number of adolescents in the population increases, the current decline in the rates of certain risk behaviors, such as teen pregnancy, will not reduce the negative impact and costs of these risk-taking behaviors. By 2010, the adolescent population in the U.S. will surpass the baby boomers' peak of 33 million in the 1970's and reach nearly 35 million. According to policy analysts, the dramatic growth in the adolescent population in the coming years requires immediate attention of program providers and policy-makers to identify and implement effective, evidence-based programs to reduce health risk behaviors (Center for the Study of Social Policy, 2003). 
Applying youth development strategies to programs designed to reduce risk behaviors is receiving increased attention. The importance of incorporating youth development strategies that build specific capabilities, competencies, skills and positive qualities into health education and prevention programs is based on numerous studies indicating that individual and environmental positive factors, or "youth assets", can insulate youth and make them less likely to engage in harmful behaviors (Benard, 1990; Garmezy, 1991; Hawkins, Catalano, Kosterman, Abbott, \& Hill, 1999; Jessor, 1991; Jessor, Van Den Bos, Vanderryn, Costa, \& Turbin, 1995; Kirby et al., 1994; McKnight, 1997; Resnick, et al., 1997; Scales, 1990).

\section{Significance}

Community involvement defined as volunteering in service to others and promoting one's community, appears to show a relationship with the reduction of several adolescent risk-taking behaviors. A major study of protective factors and risk reduction documented that youth involved in helping activities, volunteer community service or service-learning projects were less likely to be involved in anti-social behaviors, teen pregnancy, school suspensions or to drop out of school (Catalano, Berglund, Ryan, Lonczak, \& Hawkins, 1998). Studies indicated that young people who are engaged in civic activities tend to do better in school, have better psychological health, and take part in fewer risk-taking behaviors (Child Trends, 2002). Another major research report reviewed and summarized the findings of rigorously evaluated teen pregnancy prevention programs. The report found that programs involving volunteer service that was planned and led by youth showed strong evidence of effectiveness (Kirby, 2001).

Although youth development strategies have the potential to play a critical and positive role in health education and prevention programs, few studies have taken an in-depth look at the relationship among specific "youth assets" and adolescent health risk behaviors. The purpose of this study was to investigate how the Community Involvement asset may relate to eight adolescent risk behaviors (alcohol, drug, and tobacco use; sexual activity; skipping school; weapon-carrying; fighting and being arrested) and suggest implications for using Community Involvement activities to strengthen health education and prevention programs addressing risk reduction.

\section{Design}

\section{Methods}

The study involved 1350 randomly selected households containing parent-teen pairs residing in inner-city areas of two Midwestern cities. Interviews were conducted in the respondents' homes using a computer-assisted data entry system. The teenager and parent were interviewed simultaneously in different rooms of the residence. The teenager self-administered the risk behavior questionnaire by listening to tape recorded items with headphones, reading and entering responses into the computer.

Basic demographic information was collected from both the parent and teen respondents whereas youth assets and risk behaviors data were collected only from the teen. The survey response rate was $51 \%$ and included all refusals in addition to a percentage of the households for which we were unable to determine if an eligible teen lived in the household. An extensive description of the study methods is published elsewhere (Oman et al., 2002).

Youth $(N=1,278)$ mean age was 15.4 (standard deviation \pm 1.7 years) and $52 \%$ of the sample were girls. The youth sample racial-ethnic characteristics were: $48 \%$ Non-Hispanic Caucasian, 
23\% Non-Hispanic African American, 19\% Hispanic and 10\% Non-Hispanic Native American. Approximately $52 \%$ of the youth lived in one-parent households and about $79 \%$ of these singleparent households were mother only. Almost two-thirds (66\%) lived in households with reported income levels of less than $\$ 35,000$ and $13 \%$ of the youths' parents had not graduated from high school.

\section{Measures}

Demographic Variables. Depending upon the analyses, youth age was used either as a continuous variable or as a categorical variable stratified into three categories: 13 - 14 years, 15 - 17 years, and 18 - 19 years. Youth race-ethnicity was defined as Non-Hispanic African American, Non-Hispanic Native American, Non-Hispanic Caucasian, and Hispanic. Family structure was assessed via the parent and was defined as both parents living in the household or one parent living in the household. Yearly parental income was stratified into three categories: less than $\$ 20,000, \$ 20,000$ to $\$ 35,000$ and greater than $\$ 35,000$. Parental education was also stratified into three categories: both parents had less than a high school education; at least one parent had completed high school, GED, or some college; and at least one parent had a bachelor's degree or higher. Educational level of the parent not interviewed was obtained by asking the participating parent to indicate the educational level of the other parent; this was done regardless of family structure.

Youth Risk Behaviors. Youth alcohol, drug and tobacco use; sexual activity; skipping school; weapon-carrying; fighting; and arrests were the dependent variables in this study. The items used to measure each risk behavior were from the Prevention Minimum Evaluation Data Set (alcohol, drug and tobacco use, sexual activity, and skipping school), (Brindis, Peterson, Card, \& Eisen, 1998) and the Youth Risk Behavior Survey (weapon-carrying and fighting) (Oklahoma State Department of Health, 2003). One item (arrests) was created by the study group.

Since youth assets are thought to be protective against risk behaviors, the outcomes of interest were coded (in a positive direction) as the non-use of alcohol, tobacco and drugs. Non-use of alcohol was defined as answering "no" to the question, "During the past 30 days, did you drink any alcohol, such as beer, wine or liquor?" Non-use of drugs was defined as answering "no" to the question, "During the past 30 days, did you use or do any drugs such as marijuana, inhalants, methamphetamine, speed, cocaine, crack or heroin?" Non-use of tobacco was defined as answering "no" to the question, "During the past 30 days have you used any tobacco (smoked, dipped or chewed)?"

Never had sexual activity was defined as answering "no" to the question, "Have you ever had sexual intercourse ("done it", "had sex", "made love", "gone all the way")?" No skipping school was defined as answering "none" to the question, "During the last month, how many full days of school have you missed because you skipped or cut?" No weapon carrying was defined as answering " 0 days" to the question, "During the past 30 days, on how many days did you carry a weapon such as a gun, knife or club?" No physical fighting was defined as answering "0 days" to the question, "During the past 12 months, how many times were you in a physical fight?" Never been arrested was defined as answering "no" to the question, "Have you ever been arrested or picked up by the police and taken home, to youth services or jail?" The dependent behavior risk factor variables were coded so that $1=$ did not report risk factor and $0=$ did report risk factor. 
Community Involvement Asset. The Community Involvement asset was the independent variable in this study. This asset and others were identified through focus groups and needs assessment data. A literature search was conducted to identify appropriate items for asset measurement. Items with established reliability and validity from previously published research were used when possible. Items were created and pre-tested if appropriate items were not available in the literature. Factor analysis and reliability tests were used in scale construction. The Community Involvement scale was constructed using six items that all loaded at .40 and above on one factor. The reliability score (Cronbach's Alpha) for the asset was .78.

The Community Involvement asset focused on the involvement in service to others in the youth's neighborhood or larger community and their feeling of pride in or promotion of their community. The six items used as measures were:

- "You work to make your community a better place."

- "You volunteer on a regular basis to help others in your community."

- "You know where to volunteer in your community."

- "You are a person who tells others about your community."

- "You are a person who is proud to be part of your community."

- "You participate in out-of-school clubs such as Boy or Girl Scouts, volunteer or community service groups."

The response set for the first five questions included: "Not at all like you," "A little like you," "Mostly like you," or "Very much like you." The response set for the last question included: "Not at all," "Somewhat involved," or "Very involved."

Community Involvement was reported as present (1) or absent (0) on the basis of youth mean responses to the items included in the asset scale. Items comprising the scale were generally scored from 1 to 4 ( 4 = the most positive response) and an individual was said to have the asset if the individual's mean score was 3 or higher. This indicated that the positive behavior was reported as "Mostly like you" or "Very much like you."

\section{Analysis}

The sample size for the statistical analysis varied from 1247 to 1278 depending on the outcome of interest. Youth were not included in the analysis for one or more of the following: missing demographic data $(n=49)$, race-ethnicity other than those listed in Table $1(n=20)$, missing data on the Community Involvement asset $(n=3)$ or missing data on the outcome of interest. All statistical analyses were performed with SPSS for Windows, Release 10.0 (SPSS, 1999). An alpha of $\leq 0.05$ was used unless otherwise stated. Univariate associations between the Community Involvement asset and the demographic variables were assessed using a chi-square test. The unadjusted odds ratios (OR) between the Community Involvement asset and the absence of each of the eight risk factors were calculated using logistic regression. Adjusted ORs were calculated using multiple logistic regression between the Community Involvement asset and the absence of each risk factor while controlling for possible confounders. Youth age (continuous), gender and race; parent income and education; and family structure were only controlled for if the univariate analysis indicated a $p$-value of $\leq 0.10$. Interactions between each asset and each demographic variable were assessed in each logistic regression with the alpha level set at $\leq 0.01$. For significant interactions, logistic regression was conducted stratifying by the demographic variable that showed the significant interaction. 


\section{Results}

Prevalence of the Community Involvement asset differed significantly by youth race/ethnicity, youth gender and parental education (Table 1). Significant differences were found between youth racial and ethnic populations. Non-Hispanic African-American youth reported a higher prevalence of the asset than youth of other races/ethnicities. Females were more likely to report having the asset than males. There was a significant trend for parental education. As parental education increased, so did the likelihood that the youth reported having the asset.

Table 1

Frequencies and Chi-Square Values for Youth and Parent Demographics and Community Involvement Asset $(n=1278)$

\begin{tabular}{|c|c|c|c|}
\hline Youth Age $^{a}$ & No. & $\begin{array}{l}\% \text { with the Community } \\
\text { Involvement Asset }\end{array}$ & p-value \\
\hline $13-14$ & 456 & 13.6 & 0.265 \\
\hline $15-17$ & 649 & 14.0 & \\
\hline $18-19$ & 173 & 18.5 & \\
\hline \multicolumn{4}{|l|}{ Youth Race } \\
\hline Non-Hispanic African-American & 293 & 21.2 & 0.001 \\
\hline Non-Hispanic Native-American & 127 & 13.4 & \\
\hline Non-Hispanic Caucasian & 618 & 13.8 & \\
\hline Hispanic & 240 & 8.8 & \\
\hline \multicolumn{4}{|l|}{ Youth Gender } \\
\hline Female & 662 & 16.6 & 0.024 \\
\hline Male & 616 & 12.2 & \\
\hline \multicolumn{4}{|l|}{ Parental Income ${ }^{b}$} \\
\hline$<20 \mathrm{~K}$ & 395 & 13.9 & 0.195 \\
\hline $20-35 K$ & 450 & 12.7 & \\
\hline$>35 \mathrm{~K}$ & 433 & 16.9 & \\
\hline \multicolumn{4}{|l|}{ Family Structure } \\
\hline 2 Parent household & 611 & 15.5 & 0.297 \\
\hline 1 Parent household & 667 & 13.5 & \\
\hline \multicolumn{4}{|l|}{ 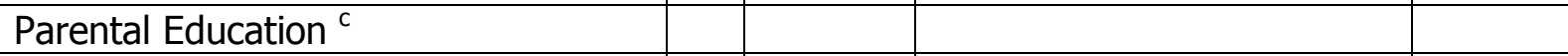 } \\
\hline$<$ High School, both parents & 161 & 9.3 & 0.095 \\
\hline $\begin{array}{l}1 \text { parent had high school, GED } \\
\text { or some college }\end{array}$ & 919 & 14.8 & \\
\hline $\begin{array}{l}\text { At least one parent had } \\
\text { bachelor's degree or higher }\end{array}$ & 198 & 17.2 & \\
\hline \multicolumn{4}{|l|}{$\begin{array}{l}\text { a Test for trend }=0.190 \\
\text { b Test for trend }=0.217 \\
\text { c Test for trend }=0.040\end{array}$} \\
\hline
\end{tabular}

Individual chi-square analysis indicated that youth with the Community Involvement asset were significantly less likely to report engaging in five of the eight risk behaviors (ever had intercourse, tobacco use, drug use, carried a weapon and been arrested) compared to youth who did not possess the asset based (Table 2). 
Table 2

Frequencies and Chi-Square Values for Youth Risk Behavior and Community Involvement Asset

\begin{tabular}{|c|c|c|c|}
\hline & No. & $\begin{array}{l}\% \text { with the Community } \\
\text { Involvement Asset }\end{array}$ & $\mathrm{p}$-value \\
\hline \multicolumn{4}{|c|}{ Ever had sexual intercourse } \\
\hline No & 781 & 16.4 & 0.024 \\
\hline Yes & 469 & 11.7 & \\
\hline \multicolumn{4}{|l|}{ Tobacco use } \\
\hline No & 942 & 16.0 & 0.009 \\
\hline Yes & 311 & 10.0 & \\
\hline \multicolumn{4}{|l|}{ Alcohol use } \\
\hline No & 994 & 15.4 & 0.065 \\
\hline Yes & 258 & 10.9 & \\
\hline \multicolumn{4}{|l|}{ Drug use } \\
\hline No & 1104 & 15.4 & 0.014 \\
\hline Yes & 143 & 7.7 & \\
\hline \multicolumn{4}{|c|}{ Skipped school any day in last month } \\
\hline No & 803 & 15.8 & 0.242 \\
\hline Yes & 343 & 13.1 & \\
\hline \multicolumn{4}{|c|}{ Carried a weapon } \\
\hline No & 1080 & 15.7 & 0.003 \\
\hline Yes & 178 & 7.3 & \\
\hline \multicolumn{4}{|c|}{ Been in a fight } \\
\hline No & 1080 & 15.7 & 0.252 \\
\hline Yes & 482 & 13.1 & \\
\hline \multicolumn{4}{|c|}{ Been Arrested } \\
\hline No & 990 & 15.6 & 0.040 \\
\hline Yes & 273 & 10.6 & \\
\hline
\end{tabular}

Table 3 shows the unadjusted and adjusted odds ratios between the Community Involvement asset and the eight risk behaviors. After adjusting for significant demographic factors, significant odds ratios were found for four of the eight risk behaviors (never had intercourse, non-use of tobacco, non-use of drugs and no weapon carrying). Youth who had the asset were nearly 1.7 times more likely to report either never having sexual intercourse or not using tobacco as compared to youth without the asset. Those with the asset were also 2 times more likely to refrain from drug use and weapon carrying as compared to youth without the asset. 
Table 3

Unadjusted and Adjusted Odds Ratios (OR) with 95\% Confidence Intervals (CI) from Individual Multiple Logistic Regression Models for Community Involvement on Various Risk Behaviors

\begin{tabular}{|c|c|c|c|c|c|}
\hline \multirow[t]{2}{*}{ Youth Asset } & \multirow[b]{2}{*}{$\mathrm{N}$} & \multicolumn{2}{|c|}{ Unadjusted } & \multicolumn{2}{|c|}{ Adjusted } \\
\hline & & OR & $95 \% \mathrm{CI}$ & OR & $95 \% \mathrm{CI}$ \\
\hline $\begin{array}{l}\text { Never had sexual } \\
\text { intercourse }\end{array}$ & 1250 & 1.48* & $(1.05,2.07)$ & $1.68^{* *, a}$ & $(1.15,2.46)$ \\
\hline Non-use of tobacco & 1253 & $1.72 * *$ & $(1.15,2.60)$ & $1.68^{*, b}$ & $(1.08,2.60)$ \\
\hline Non-use of alcohol & 1252 & 1.49 & $(0.97,2.29)$ & \multicolumn{2}{|c|}{ Interaction } \\
\hline Non-use of drugs & 1247 & $2.18^{*}$ & $(1.16,4.13)$ & $2.01^{*, c}$ & $(1.06,3.83)$ \\
\hline No skipping school & 1146 & 1.24 & $(0.86,1.80)$ & $1.23^{\mathrm{b}}$ & $(0.84,1.80)$ \\
\hline No weapon carrying & 1258 & $2.37 * *$ & $(1.32,4.27)$ & $2.00^{*}, \mathrm{~d}$ & $(1.10,3.66)$ \\
\hline No physical fighting & 1274 & 1.21 & $(0.87,1.68)$ & $1.07^{\mathrm{e}}$ & $(0.76,1.51)$ \\
\hline Never been arrested & 1263 & $1.55 *$ & $(1.02,2.36)$ & $1.48^{\mathrm{e}}$ & $(0.96,2.27)$ \\
\hline \multicolumn{6}{|c|}{$\begin{array}{l}\text { Adjusted for youth age, parental income and education, and family structure } \\
\text { bAdjusted for youth age and race, parental income and education, and family structure } \\
\text { cAdjusted for youth age and race, and family structure } \\
\text { dAdjusted for youth age, gender, and race } \\
\text { eAdjusted for youth age and gender, parental income and education, and family structure } \\
{ }^{*} p \leq 0.05,{ }^{* *} \leq 0.01\end{array}$} \\
\hline
\end{tabular}

There was an interaction between the asset and alcohol use for family structure (Table 4). Youth who had the asset and who lived in a household with one parent were almost 2.6 times more likely to not use alcohol compared to youth who lived with one parent and who did not have the asset.

Table 4

Adjusted Parental Income Specific Odds Ratios (OR) with 95\% Confidence Intervals (CI) from Individual Multiple Logistic Regression Models for Non-use of Alcohol

\begin{tabular}{|l|l|l|l|}
\hline & & \multicolumn{2}{|c|}{ Adjusted } \\
\hline & \multicolumn{1}{|c|}{$\mathrm{N}$} & \multicolumn{1}{|c|}{ OR } & $95 \%$ CI \\
\hline Community Involvement ${ }^{1}$ & & & \\
\hline Family Structure & & & $(0.44,1.45)$ \\
\hline 2 parent household & 601 & 0.80 & $(1.26,5.15)$ \\
\hline 1 parent household & 651 & $2.55^{*}$ & \multicolumn{3}{|l}{} \\
\hline $\begin{array}{l}{ }^{1} \text { Adjusted for youth age and race } \\
{ }^{*} \mathrm{p} \leq 0.01\end{array}$
\end{tabular}

\section{Implications for Practice}

Research indicates that effective youth development programs feature challenging opportunities for self-direction and for participation and contribution within an organization and community (Pittman, 2002). Previous research of protective factors and risk reduction documented that youth involved in helping activities, volunteer community service or service-learning projects 
were less likely to be involved in anti-social behaviors, teen pregnancy, school suspensions or to drop out of school (Catalano, Berglund, Ryan, Lonczak, \& Hawkins, 1998).

The purpose of this study was to explore the relationship between the Community Involvement asset and eight youth risk behaviors. After adjusting for relevant demographic characteristics, results suggested that youth with this asset were more likely to never have had sexual intercourse, be non-users of tobacco and drugs, not have carried a weapon; and for children in one-parent households, to be non-users of alcohol. Although the results suggest that the Community Involvement asset is protective for several youth risk behaviors, further research is necessary to test the assumption that the asset is causally linked to a reduction in these risk behaviors. These preliminary findings support the notion that community-focused volunteer service activities may increase the effectiveness of youth development efforts designed to reduce specific adolescent risk-taking behaviors. Practical implications are thus offered from within the context of the limitations of cross-sectional data.

The Community Involvement asset was found to be more prevalent among females, which is consistent with previous studies (U.S. Department of Education, 1997). It has been hypothesized that girls are more likely to have an ethic of care than boys and that such attitudes are consistent with community service (Karniol, Grosz, \& Schorr, 2003). The asset was also more prevalent among certain racial/ethnic and socioeconomic groups, implying that an expansion of volunteer service and community involvement opportunities may hold potential for reducing adolescent risk behaviors among specific youth populations.

Community involvement activities, by their nature, expose youth to experiences that are likely to include the opportunity to build relationships with caring and supportive adults. (National Research Council and Institute of Medicine, 2002). Previous research has shown that the Adult Role Models asset has a strong relationship with the non-use of tobacco and drugs among youth and a reduction in sexual activity, fighting and weapon-carrying (Aspy, et al., 2004; Oman, et al., 2004; Vesely, et al., 2004).

Although previous research has supported the notion that these assets are independent constructs associated with specific risk behaviors, research also suggests that multiple assets increase the potential for lower risk-taking behaviors in adolescents (Oman, Vesely, Aspy, McLeroy, \& Luby, 2004). Therefore, increasing the involvement within the community may simultaneously help develop not only the community involvement asset but also other youth assets that may also serve as protective factors against risk behaviors.

Results of this study appear to support those of other studies that found that youth engagement in service to others and their community can play an important role in the healthy development of young people (Benson, Leffert, Scales, \& Blyth, 1998; Scales \& Leffert, 2003; O'Donnell, Stueve, Doval, Duran, Haber, Atnafou, et al., 1999), as well as increase the effectiveness of health and prevention programs (Pittman, Irby, Tolman, Yohalem, \& Ferber, 2003).

\section{Limitations}

In this study, alcohol, drug and tobacco use were assessed only for the past 30 days, and therefore it is unknown what behavior occurred outside this time period. Also, the youth may have provided inaccurate, socially acceptable responses to the risk behavior questions even though they were allowed to read the questions, listen by headphones and enter their responses into a computer unobserved. This protocol may have reduced the number of socially 
acceptable responses. Also, the moderate response rate raises questions about the generalizability of the results. However, no significant differences were found when the racial/ethnic and household income results from the sample were compared by zip codes to census data from the same neighborhoods, suggesting that the sample was representative of the intervention neighborhoods. Finally, the data analyzed in this study was cross-sectional, thus causal relationships between the assets and the risk behaviors cannot be tested.

\section{Conclusions}

In summary, this study found that the Community Involvement asset was related to youth decisions to not participate in a number of risk-taking behaviors, suggesting that engaging young people in volunteer service experiences in their communities holds potential as a protective factor in reducing certain adolescent health risk behaviors. In addition to appearing to serve as a protective factor itself, activities that strengthen the Community Involvement asset often include other youth assets, including positive relationships with caring adults, positive peer relationships and constructive use of time. Thus, increasing the Community Involvement asset among young people may result in an increase in multiple protective factors at the same time.

The influence of Community Involvement remains an understudied area, especially as it may causally relate to specific risk behaviors, populations, age groups and the exact type and duration of a young person's volunteer experience. More research is needed to examine the relationship between youth involvement in volunteer community service and adolescent health risk reduction to determine how this asset can be applied most effectively in programs designed to reduce specific health risk behaviors.

\section{References}

Aspy, C.B., Oman, R.F., Vesely, S.K., McLeroy, K., Harris-Wyatt, V., Rodine, S., et al. (2004). Adolescent violence: The protective effects of youth assets. Journal of Counseling and Development, 82, 269-277.

Benard, B. (1990). Youth service: From youth as problems to youth as resources. Prevention Forum, January, 6-14.

Benson, P.L., Leffert N., Scales, P.C., \& Blyth, D. (1998). Beyond the "village" rhetoric: Creating healthy communities for children and adolescents. Applied Developmental Science, 2(3), 138159.

Brindis, C., Peterson, L.J., Card, J.J., \& Eisen, M. (1998). Prevention minimum evaluation data set (PMEDS): A minimum data set for evaluating programs aimed at preventing adolescent pregnancy and STD/AIDS. Los Altos, CA: Sociometrics Corporation.

Catalano, R.F., Berglund, M.L., Ryan, J.A., Lonczak, H.S., \& Hawkins, J.D. (1998). Positive youth development in the United States. Retrieved July 15, 2002, from http://aspe.hhs.gov/hsp/PositiveYouthDev99/ 
Center for the Study of Social Policy. (2003). Engaging youth in positive and productive roles: Recommendations for state policy. Washington, D.C.

Child Trends. (2002). Building a better teenager: A summary of what works in adolescent development. Washington, D.C.: Child Trends, Inc.

Garmezy, N. (1991). Resiliency and vulnerability to adverse developmental outcomes associated with poverty. American Behavioral Scientist, 34, 416-430.

Hawkins, J.D., Catalano, R.F., Kosterman, R., Abbott, R., \& Hill, K.G. (1999). Preventing adolescent health-risk behaviors by strengthening protection during childhood. Archives of Pediatrics \& Adolescent Medicine, 153, 226-234.

Jessor, R.J. (1991). Risk behavior in adolescence: A psychosocial framework for understanding and action. Journal of Adolescent Health, 12, 597-605.

Jessor, R.J., Van Den Bos, J., Vanderryn, J., Costa, F.M., \& Turbin, M.S. (1995). Protective factors in adolescent problem behavior: Moderator effects and developmental change.

Developmental Psychology, 31, 923-933.

Karniol, R. Grosz, E, \& Schorr, I. (2003). Caring, gender role orientation, and volunteering. Sex Roles, 49, 11-19.

Kirby, D. (2001). Emerging answers: Research findings on programs to reduce teen pregnancy (summary). Washington, D.C.: National Campaign to Prevent Teen Pregnancy.

Kirby, D., Short, L., Collins, J., Rugg, D., Kolbe, L., Howard, M., et al. (1994). School-based programs to reduce sexual risk behavior: A review of effectiveness. Public Health Reports, 109, 339-360.

McKnight, J.L. (1997). A 21st century map for healthy communities and families. Families in Society, March/April, 117-127.

National Research Council and Institute of Medicine. (2002). Community programs to promote youth development. Washington, D.C.: National Academy Press.

O'Donnell, L., Stueve, A., Doval, A., Duran, R., Haber, D., Atnafou, R., et al., (1999). The effectiveness of the Reach for Health Community Youth Service Learning Program in reducing early and unprotected sex among urban middle school students. American Journal of Public Health, 89, 176-181.

Oklahoma State Department of Health. (2003). Oklahoma youth risk behavior survey. Oklahoma City, Ok: Oklahoma State Department of Health, Maternal and Child Health Division.

Oman, R.F., McLeroy, K., Vesely, S.K., Aspy, C.B., Smith, D.W., \& Penn, D.A. (2002). An adolescent age group approach to examining youth risk behaviors. American Journal of Health Promotion, 16, 167-176. 
Oman, R.F., Vesely, S.K., Aspy, C.B., McLeroy, K., Rodine, S., \& Marshall, L. (2004). The potential protective effect of youth assets on adolescent alcohol and drug use. American Journal of Public Health, 94, 1425-1430.

Oman, R.F., Vesely, S.K., Aspy, CB., McLeroy, K., \& Luby, C. (2004). The association between multiple youth assets and sexual behavior. American Journal of Health Promotion, 19(1), 12-18.

Pittman, K. (2002). Making the most of the national research council's new report: Community programs to promote youth development. The Forum for Youth Investment Commentary.

Pittman, K., Irby, M., Tolman, J., Yohalem, N., \& Ferber, T. (2003). Preventing problems, promoting development, encouraging engagement: Competing priorities or inseparable goals? Washington D.C.: The Forum for Youth Investment: Impact Strategies, Inc.

Resnick, M.D., Bearman, P.S., Blum, R.W., Bauman, K.E., Harris, K.M., Jones, J., et al. (1997). Protecting adolescents from harm: Findings from the national longitudinal study on adolescent health. Journal of the American Medical Association, 278, 823-832.

Scales, P.C. (1990). Developing capable young people: An alternative strategy for prevention programs. Journal of Early Adolescence, 10, 420-438.

Scales, P.C. \& Leffert, N. (2003) The relation of community developmental attentiveness to adolescent health. American Journal of Health Behavior, Suppl 1, S22-34.

SPSS. (1999). SPSS base 10.0 applications guide. Chicago, IL: SPSS.

U.S. Department of Education. (1997). Student participation in community service activity (NCES Publication No. 97-331). Washington, D.C.

Vesely, S.K., Wyatt, V.H., Oman, R.F., Aspy, C.B., Kegler, M., Rodine, S., et al. (2004). The potential protective effects of youth assets from adolescent sexual risk behaviors. Journal of Adolescent Health, 34, 356-365.

This project was supported under a cooperative agreement from the Centers for Disease Control and Prevention (CDC) through the Association of Schools of Public Health (ASPH) Grant Number U36/CCU300430. The contents of this article are solely the responsibility of the authors and do not necessarily represent the official views of CDC or ASPH.

(C) Copyright of Journal of Youth Development Bridging Research and Practice. Content may not be copied or emailed to multiple sites or posted to a listserv without copyright holder's express written permission. Contact Editor at: patricia.dawson@oregonstate.edu for details. However, users may print, download or email articles for individual use.

ISSN 2325-4009 (Print); ISSN 2325-4017 (Online) 